\title{
Association of extrapituitary prolactin promoter polymorphism with disease susceptibility and anti-RNP antibodies in Mexican patients with systemic lupus erythematosus
}

\author{
Jorge Hernández-Bello¹, Claudia A. Palafox-Sanchez¹, Samuel García-Arellano, \\ Zyanya Reyes-Castillo ${ }^{1}$, Ana L. Pereira-Suárez ${ }^{1}$, Isela Parra-Rojas², José E. Navarro-Zarza³, \\ Ulises De la Cruz-Mosso ${ }^{1}$, Nora M. Torres-Carrillo ${ }^{1}$, José Francisco Muñoz-Valle ${ }^{1}$
}

\begin{abstract}
${ }^{1}$ Instituto de Investigación en Ciencias Biomédicas, Centro Universitario de Ciencias de la Salud, Universidad de Guadalajara, Guadalajara, Jalisco, México

2Unidad Académica de Ciencias Químico Biológicas, Universidad Autónoma de Guerrero, Chilpancingo de los Bravo, Guerrero, México

${ }^{3}$ Departamento de Medicina Interna-Reumatología, Hospital General de Chilpancingo "Dr. Raymundo Abarca Alarcón", Chilpancingo de los Bravo, Guerrero, México
\end{abstract}

Submitted: 7 April 2016

Accepted: 21 July 2016

Arch Med Sci 2018; 14, 5: 1025-1032

DOI: https://doi.org/10.5114/aoms.2016.62138

Copyright $\odot 2016$ Termedia \& Banach

\section{Abstract}

Introduction: Prolactin (PRL) is a $23-k D a$ protein that can be synthesized and secreted by pituitary and extrapituitary tissues such as immune cells due to its expression being regulated by two independent promoter regions. The promoter which is responsible for extrapituitary expression contains the single nucleotide polymorphism (SNP) $-1149 \mathrm{G} / \mathrm{T}$ previously associated with autoimmune diseases in various populations. This study evaluates the relationship of PRL $-1149 \mathrm{G} / \mathrm{T}$ polymorphism with PRL serum levels and clinical characteristics in systemic lupus erythematosus (SLE) patients from western Mexico.

Material and methods: One hundred and sixty-three SLE patients classified according to the 1982 American College of Rheumatology (ACR) SLE classification criteria and 326 unrelated control subjects (CS), both from western Mexico, were included. The PRL $-1149 \mathrm{G} / \mathrm{T}$ polymorphism was genotyped using the polymerase chain reaction restriction fragment length polymorphism technique, and both PRL serum levels and autoantibodies were measured by enzyme-linked immunosorbent assay (ELISA).

Results: We found an association between the PRL -1149 TT genotype and SLE according to the recessive genetic model $(\mathrm{OR}=2.26,95 \% \mathrm{Cl}: 1.01-5.08$, $p=0.04$ ). The TT genotype was associated with anti-RNP antibodies ( $p=$ $0.04)$ and with higher scores of the Mex-SLEDAI $(p=0.02)$. Moreover, SLE patients showed elevated PRL serum levels (12.4 $\mathrm{ng} / \mathrm{ml} ; p<0.01)$, and this condition was associated with renal activity and the presence of anti-RNP antibodies.

Conclusions: PRL -1149 TT genotype is associated with susceptibility to SLE in a Mexican-Mestizo population, and high PRL serum levels are associated with anti-RNP antibodies and renal activity.

Key words: systemic lupus erythematosus, prolactin, genetic polymorphism, autoimmunity, anti-RNP antibodies.

\author{
Corresponding author: \\ José Francisco \\ Muñoz-Valle PhD \\ Instituto de Investigación \\ en Ciencias Biomédicas \\ Centro Universitario \\ de Ciencias de la Salud \\ Universidad \\ de Guadalajara \\ Insurgentes 244-1 \\ Lomas de Atemajac \\ 45178 Zapopan, Jalisco, \\ México \\ Phone: +52 10585200, \\ ext. 34200 \\ E-mail: biologiamolecular@ \\ hotmail.com
}


J. Hernández-Bello, C.A. Palafox-Sanchez, S. García-Arellano, Z. Reyes-Castillo, A.L. Pereira-Suárez, I. Parra-Rojas, J.E. Navarro-Zarza, U. De la Cruz-Mosso, N.M. Torres-Carrillo, J.F. Muñoz-Valle

\section{Introduction}

Systemic lupus erythematosus (SLE) is an autoimmune disease characterized by systemic chronic inflammation that can affect multiple organ systems as well as by the presence of autoantibodies directed against nuclear and cytoplasmic antigens [1].

To date the etiology of SLE is unknown, but it has been suggested that genetic, epigenetic, environmental, hormonal, and immunoregulatory factors may contribute to the initiation and development of this complex disorder [2]. A strong risk factor for development of SLE is female gender, since it is more common in women than men, with a ratio of $9: 1$, suggesting that endocrine factors modulate the susceptibility and development of $\operatorname{SLE}[3,4]$. Prolactin (PRL) is an important hormone with multiple biological functions such as reproduction, pregnancy, growth, development, metabolism and immune modulation, among other functions $[5,6]$. It is produced in the pituitary gland and other extrapituitary sites, including tissues and cells of the immune system, upon which it exerts immunostimulatory and lymphoproliferative effects [7].

Prolactin induces the release of interleukin-2 (IL-2), increases IL-2 receptor expression and interferon- $\gamma$ levels in lymphocytes, and potentiates IL-2-induced proliferation of natural killer cells. In addition, PRL has also been shown to have an effect on dendritic cell maturation in synergy with granulocyte-macrophage colony-stimulating factor, and it is associated with increased antibody production by human lymphocytes and in mice [8]. Also it has been reported that enhanced PRL production in lymphocytes occurs in patients with autoimmune diseases, and it has been related to the induction of autoimmunity [9].

In humans, prolactin concentrations have been found to be elevated in some patients with SLE [8]. About $25-30 \%$ of the patients have mild-to-moderately increased prolactin serum levels [10], and although some authors show that this increase in PRL levels could be correlated with clinical disease activity and presence of autoantibodies [7, $11,12]$, other research groups have refuted these findings [13, 14]; probably these discrepancies could be explained by the genetic background of each individual [15].

The human PRL gene is situated on the short arm of chromosome 6 and has two independent promoter regions which regulate transcription of the PRL gene [16], the proximal region directs the pituitary-specific expression, while a more upstream promoter region named the "super distal promoter" directs the extrapituitary PRL expression [17]. The super distal promoter contains a single nucleotide polymorphism (SNP) at position -1149 $\mathrm{G} / \mathrm{T}$ (rs1341239), which has been shown to affect $P R L$ gene transcription in lymphocytes [8]. This polymorphism has been associated with susceptibility to SLE in different populations $[8,18,19]$ nevertheless, these findings are not consistent [20].

To date and to the best of our knowledge, no reports have been published regarding the role of the extrapituitary $P R L$ promoter polymorphism in SLE patients from western Mexico. Therefore, the aim of this study was to evaluate the association of the extrapituitary $P R L-1149 \mathrm{G} / \mathrm{T}$ promoter polymorphism with susceptibility to SLE as well as their relationship with clinical parameters, clinical activity and disability indices in SLE patients from western Mexico.

\section{Material and methods}

\section{Study population}

One hundred sixty-three patients with SLE from the Department of Rheumatology of the Hospital General de Occidente, Zapopan, Jalisco, México were included. All patients fulfilled the 1982 American College of Rheumatology (ACR) SLE classification criteria [21]. Mex-SLEDAI (Mexican Systemic Lupus Activity Index) and Systemic Lupus International Collaborating Clinics/ACR Damage Indexes (SLICC) [22] at the beginning of the study were evaluated. The control subjects comprised 326 healthy individuals (identified by self-report) recruited from the general population. The SLE patients and CS were unrelated subjects from the same Mexican population. Informed written consent was obtained from all individuals before their enrollment in the study. The study was performed according to the ethical guidelines stated in the Declaration of Helsinki, and it is in compliance with all ethical standards in medicine.

\section{Laboratory assessment and quantification of antibodies}

Erythrocyte sedimentation rate (ESR) was quantified by the Wintrobe method. Double strain DNA (dsDNA), anti-Ro, anti-La, anti-Sm and anti-Sm/ RNP antibody levels were measured with an enzyme-linked immunosorbent assay (ELISA) according to the manufacturer's recommendations (Binazyme ELISA Kits, The Binding Site Ltd., Birmingham, UK).

\section{PRL quantification}

In order to obtain reliable results, a stricter selection of individuals was done for the measurement of PRL serum levels. A subset of 117 female patients with SLE and 117 female CS matched by age were analyzed. Exclusion criteria included pregnancy and diseases or medication known to affect PRL serum concentrations. The quantification of PRL serum levels was performed using 
a commercial ELISA kit (EIA-1291; DRG, International). The sensitivity limit of the assay was 0.35 $\mathrm{ng} / \mathrm{ml}$. Hyperprolactinaemia (HPRL) was defined as PRL serum levels $>20 \mathrm{ng} / \mathrm{ml}$.

\section{PRL -1149 G/T polymorphism genotyping}

The genomic DNA from the patients and controls were obtained from peripheral blood leukocytes according to standard procedures [23]. Genotyping of the $P R L-1149 \mathrm{G} / \mathrm{T}$ polymorphism was performed by the polymerase chain reaction restriction fragment length polymorphism (PCR-RFLP) method, using previously reported conditions [24]. The genotyping technique for the $P R L-1149 \mathrm{G} / \mathrm{T}$ polymorphism was confirmed by DNA sequencing of a subset of samples, randomly selected, through a DNA Genetic Analyzer ABI Prism 310 (Applied Biosystems, Foster, California) (data not shown).

\section{Statistical analysis}

Statistical analysis was performed using the statistical software STATA $\vee 9.2$ and GraphPad Prism $\vee$ 5.0. For the descriptive analysis, nominal variables were expressed as frequencies, and continuous variables not normally distributed were expressed as medians, 5 to 95 percentiles and 25 to 75 interquartiles, and variables normally distributed were expressed as mean \pm SD. Allelic and genotypic frequencies were obtained by direct counting. Hardy-Weinberg equilibrium was evaluated with the $\chi^{2}$ test. Comparison of allele and genotype distribution was performed using Pearson's $\chi^{2}$ test, and the dominant and recessive genetic models for the polymorphism were also evaluated [25]; the odds ratio (OR) and 95\% confidence interval $(95 \% \mathrm{Cl})$ were estimated to analyze the risk of PRL genotypes associated with SLE. Differences in clinical parameters among SLE patients vs. CS, or among carriers of GG, GT and TT genotypes were evaluated by Student's $t$ test, the Mann-Whitney $U$ test or the Kruskal-Wallis test, as appropriate. A probability ( $p$ ) value of less than 0.05 was considered significant.

\section{Results}

\section{Demographic and clinical features}

The demographic and clinical data of SLE patients enrolled in the study are shown in Table I. The mean age of the patients was 36 (18-65) years; $96 \%$ were female and $4 \%$ were male. The average evolution time of the disease was $6(0-25)$ years, and the subjects had a moderate activity disease score (2; 0.0-9.0) according to Mex-SLEDAI. The majority of patients were treated mainly with prednisone (52\%) and azathioprine (44\%). The control group included 326 healthy subjects com- posed of $64 \%$ women and $36 \%$ men with a median age of 36 (23-61) years.

\section{PRL -1149 G/T polymorphism in SLE} patients and control subjects

The genotypic and allelic frequencies of the $P R L$ $-1149 \mathrm{G} / \mathrm{T}$ polymorphism in both SLE patients and

Table I. Demographic and clinical characteristics of Mexican SLE patients

\begin{tabular}{|c|c|}
\hline Variables & $\operatorname{SLE}(N=163)$ \\
\hline \multicolumn{2}{|c|}{ Demographic characteristics: } \\
\hline Age [years] ${ }^{a}$ & $36(18-65)$ \\
\hline \multicolumn{2}{|l|}{ Gender, $n(\%)^{\mathrm{b}}$ : } \\
\hline Female & $156(96)$ \\
\hline Male & $7(4)$ \\
\hline Disease duration [year] ${ }^{\mathrm{a}}$ & $6(0-25)$ \\
\hline \multicolumn{2}{|l|}{ Clinical assessment: } \\
\hline Mex-SLEDAI, score ${ }^{a}$ & $2(0-9)$ \\
\hline SLICC, score ${ }^{a}$ & $0(0-2)$ \\
\hline $\mathrm{ESR}[\mathrm{mm} / \mathrm{h}]^{\mathrm{c}}$ & $32 \pm 14$ \\
\hline Renal activity, $n(\%)^{\mathrm{b}}$ & $14(9)$ \\
\hline $\mathrm{CRF}, n(\%)^{\mathrm{b}}$ & $8(5)$ \\
\hline $\mathrm{PRL}[\mathrm{ng} / \mathrm{ml}]^{\mathrm{a}}$ & $7.5(2.8-18.8)$ \\
\hline \multicolumn{2}{|l|}{ Autoantibodies, $n(\%)^{\mathrm{b}}$ : } \\
\hline ANAs & $120(74)$ \\
\hline Anti-dsDNA & $72(44)$ \\
\hline Anti-La & $7(4)$ \\
\hline Anti-Ro & $16(10)$ \\
\hline Anti-Sm & $11(7)$ \\
\hline Anti-RNP & $18(11)$ \\
\hline \multicolumn{2}{|l|}{ Drug treatment, $n(\%)^{\mathrm{b}}$ : } \\
\hline NSAIDs: & $7(4)$ \\
\hline \multicolumn{2}{|l|}{ Corticosteroids } \\
\hline Prednisone & $85(52)$ \\
\hline \multicolumn{2}{|l|}{ DMARDs: } \\
\hline Methotrexate & $19(12)$ \\
\hline Azathioprine & $71(44)$ \\
\hline Chloroquine & $52(32)$ \\
\hline Hydroxychloroquine & $15(9)$ \\
\hline Cyclophosphamide & $11(7)$ \\
\hline
\end{tabular}

${ }^{a}$ Data provided as median (p5-p95). ${ }^{b}$ Data provided as percentages and $n .{ }^{c}$ Data provided as mean $\pm S D$. Mex-SLEDAI - Mexican version of the Systemic Lupus Erythematosus, Disease Activity Index; SLICC - Systemic Lupus International Collaborating ClinicS, ESR erythrocyte sedimentation rate, CRF - chronic renal failure, NSAIDs - non-steroidal anti-inflammatory drugs, DMARDS - diseasemodifying antirheumatic drugs. 
J. Hernández-Bello, C.A. Palafox-Sanchez, S. García-Arellano, Z. Reyes-Castillo, A.L. Pereira-Suárez, I. Parra-Rojas, J.E. Navarro-Zarza, U. De la Cruz-Mosso, N.M. Torres-Carrillo, J.F. Muñoz-Valle

CS are shown in Table II. Our population was in agreement with the Hardy-Weinberg equilibrium ( $p>0.05$; data not shown). When we compared the genotypic frequencies between SLE patients and controls, we observed a significant difference $(p=0.02)$. We also analyzed the distribution of the polymorphism by applying genetic models of inheritance (dominant and recessive), and according to the recessive genetic model there is an association between the TT genotype and increased SLE susceptibility $(\mathrm{OR}=2.26,95 \% \mathrm{Cl}: 1.01-5.08$; $p=0.04)$.

\section{PRL -1149 G/T polymorphism and clinical parameters in SLE}

The clinical parameters were compared according to the recessive genetic model of the $P R L$ -1149 polymorphism (Table III). We found a significant difference between TT genotype carriers and non-carriers in the presence of anti-RNP antibody $(p=0.04)$, since the anti-RNP antibodies were more frequent in the TT genotype carriers in comparison with the GT + GG carriers. In addition, the TT genotype carriers had higher damage (SLICC, $p=0.02$ ) compared to the GT + GG carriers.

\section{PRL serum levels in SLE patients and control subjects}

We found a significant difference in the PRL serum levels between SLE patients and CS (7.5 vs. $5.3 \mathrm{ng} / \mathrm{ml} ; p<0.001$; Figure $1 \mathrm{~A})$. Moreover, we observed HPRL status (values > $20 \mathrm{ng} / \mathrm{ml}$ ) in $5.9 \%$ of the SLE patients. Additionally, to evidence the participation of $P R L$ in evolution of the disease, we compared PRL serum levels in SLE patients according to evolution time of the disease, and we found that the patients with $<1$ year of evolution had higher PRL serum levels compared to patients with $>1$ year of evolution ( $p=0.02$; Figure $1 \mathrm{~B}$ ).

The relationship between the PRL levels and other markers of lupus activity was also tested; anti-RNP antibody positive patients had higher PRL serum levels than anti-RNP antibody negative patients ( $p=0.004$; Figure $1 \mathrm{C}$ ). Similarly, we observed that SLE patients with renal activity had higher PRL serum levels compared with SLE patients without renal activity $(p=0.03$; Figure $1 \mathrm{D}$ ).

On the basis of the MEX-SLEDAI score, patients were identified with remission (MEX-SLEDAI scores $<2$ ), low-to-moderate activity (MEX-SLEDAI scores 2 to $<8$ ), and severe disease activity (MEX-SLEDAI scores $\geq 8$ ). Higher median PRL levels were observed in the severe disease activity group in compared to others, although the difference did not reach statistical significance (Figure 2). Moreover, we found a negative correlation between PRL serum levels and age $(p<0.001$; data not shown). Finally, to analyze the impact of the $P R L-1149 \mathrm{G} / \mathrm{T}$ SNP on total PRL serum levels we performed a recessive inheritance genetic model according to $P R L-1149 \mathrm{G} / \mathrm{T}$ genotypes in SLE patients and CS. We found a significant difference in the frequency of GG + GC genotype between SLE patients and CS $(p=0.002)$. Such a difference was also observed in the frequency of TT genotype, but the difference was not statistically significant (Figure 3).

Table II. Distribution of $P R L-1149 \mathrm{G} / \mathrm{T}$ polymorphism among SLE patients and CS

\begin{tabular}{|c|c|c|c|c|}
\hline $\begin{array}{l}\text { SNP } \\
-1149 \mathrm{G} / \mathrm{T} \\
\text { (rs1341239) }\end{array}$ & $\begin{array}{c}\text { SLE } \\
(N=163) \\
n(\%)^{\mathrm{a}}\end{array}$ & $\begin{array}{c}C S \\
(N=326) \\
n(\%)^{\mathrm{a}}\end{array}$ & $P$-value ${ }^{a}$ & OR $(95 \% \mathrm{Cl}) ;{ }^{\S} p$ \\
\hline \multicolumn{5}{|l|}{ Genotype: } \\
\hline$G^{b}$ & $101(62)$ & $185(56)$ & 0.02 & 1.0 \\
\hline GT & $49(30)$ & $129(40)$ & & $0.69(0.46-1.04) ; 0.08$ \\
\hline TT & $13(8)$ & $12(4)$ & & $1.98(0.87-4.51) ; 0.10$ \\
\hline \multicolumn{5}{|l|}{ Allele: } \\
\hline$G^{b}$ & $251(77)$ & $499(76)$ & 0.87 & 1.0 \\
\hline $\mathrm{T}$ & $75(23)$ & $153(24)$ & & $0.97(0.70-1.35) ; 0.87$ \\
\hline \multicolumn{5}{|l|}{ Do: } \\
\hline $\mathrm{GG}^{\mathrm{b}}$ & $101(62)$ & $185(57)$ & 0.27 & 1.0 \\
\hline $\mathrm{GT}+\mathrm{TT}$ & $62(38)$ & $141(43)$ & & $0.80(0.54-1.18) ; 0.27$ \\
\hline \multicolumn{5}{|l|}{ Re: } \\
\hline $\mathrm{GG}+\mathrm{GT}^{\mathrm{b}}$ & $150(92)$ & 314 (96) & 0.04 & 1.0 \\
\hline TT & $13(8)$ & $12(4)$ & & $2.26(1.01-5.08) ; 0.04$ \\
\hline
\end{tabular}

Percentages were obtained by direct count. SLE - systemic lupus erythematosus; CS - control subjects; OR - odds ratio; $95 \%$ CI - 95\% confidence interval; Do - dominant genetic model; Re - recessive genetic model. ${ }^{\mathrm{a}} p$-value was calculated by $\chi^{2}$ test. ${ }^{\mathrm{b}}$ Reference category, sp value was calculated by logistic regression. 
Association of extrapituitary prolactin promoter polymorphism with disease susceptibility and anti-RNP antibodies in Mexican patients with systemic lupus erythematosus

Table III. Clinical characteristics of SLE patients according to PRL $-1149 \mathrm{G} / \mathrm{T}$ polymorphism

\begin{tabular}{|c|c|c|c|}
\hline Variable & $\begin{array}{c}\mathrm{GG}+\mathrm{GT} \\
(N=150)\end{array}$ & $\begin{array}{c}\mathrm{TT} \\
(N=13)\end{array}$ & $P$-value \\
\hline \multicolumn{4}{|c|}{ Clinical activity and disability: } \\
\hline Mex-SLEDAI, score ${ }^{\mathrm{a}}$ & $2(0-8)$ & $1(0-11)$ & 0.68 \\
\hline SLICC, score ${ }^{a}$ & $0(0-2)$ & $1(0-3)$ & 0.02 \\
\hline ESR $[\mathrm{mm} / \mathrm{h}]^{\mathrm{c}}$ & $31.9 \pm 14.1$ & $36.8 \pm 12.5$ & 0.32 \\
\hline Renal activity, $n(\%)^{\mathrm{b}}$ & $13(8.6)$ & $1(7.7)$ & 0.67 \\
\hline $\mathrm{CRF}, n(\%)^{\mathrm{b}}$ & $7(4.7)$ & $1(7.7)$ & 0.50 \\
\hline Arthritis, $n(\%)^{b}$ & $19(12.7)$ & $1(7.7)$ & 0.72 \\
\hline $\mathrm{PRL}[\mathrm{ng} / \mathrm{ml}]^{\mathrm{a}}$ & $7.3(2.9-17.2)$ & $10.12(2.4-17.2)$ & 0.38 \\
\hline \multicolumn{4}{|l|}{ Autoantibodies, $n(\%)^{\mathrm{b}}$ : } \\
\hline ANAs & $111(74)$ & $9(69)$ & 0.65 \\
\hline Anti-dsDNA & $64(43)$ & $8(61.5)$ & 0.29 \\
\hline Anti-La & $7(4.7)$ & $0(0)$ & 0.71 \\
\hline Anti-Ro & $16(10.7)$ & $0(0)$ & 0.44 \\
\hline Anti-Sm & $10(6.7)$ & $1(7.7)$ & 0.47 \\
\hline Anti-RNP & $15(10)$ & $3(23.1)$ & 0.04 \\
\hline
\end{tabular}

${ }^{a}$ Data provided as median ( $\left.p 5-p 95\right)$, Mann-Whitney $U$ test. ${ }^{b}$ Data provided as $n$ and percentages, Fisher exact test. ${ }^{c} D a t a$ provided as mean \pm SD, Student $t$ test. Mex-SLEDAI - Mexican version of the Systemic Lupus Erythematosus, Disease Activity Index, SLICC - Systemic Lupus International Collaborating Clinics, ESR - erythrocyte sedimentation rate, CRF - chronic renal failure.

A

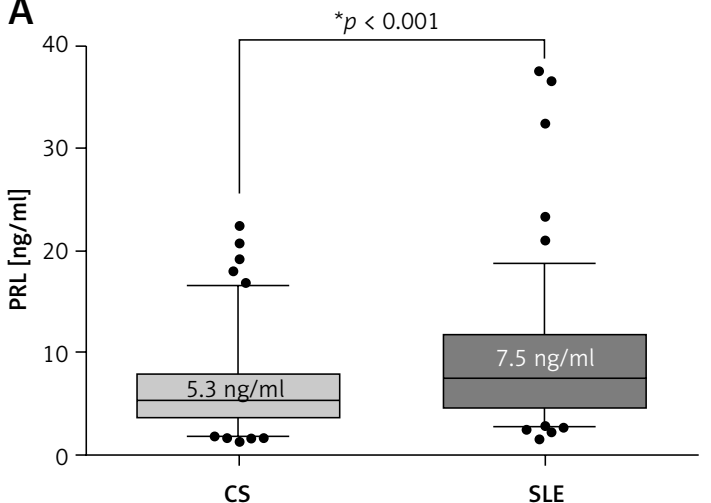

CS

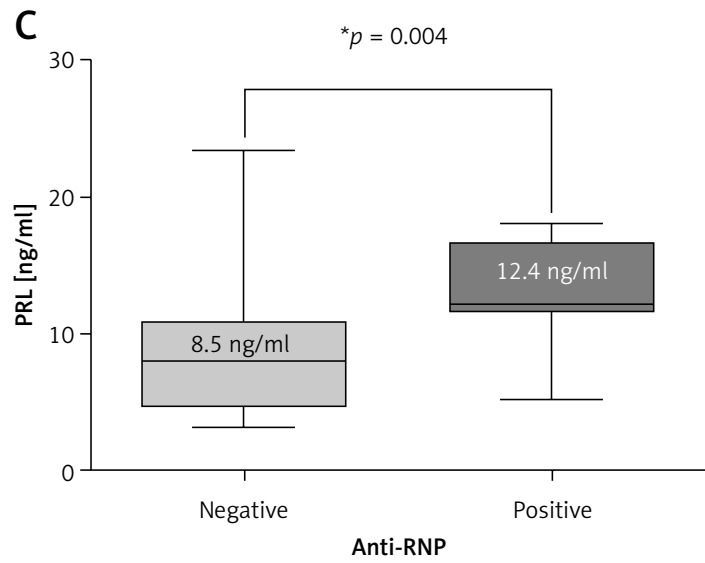

B

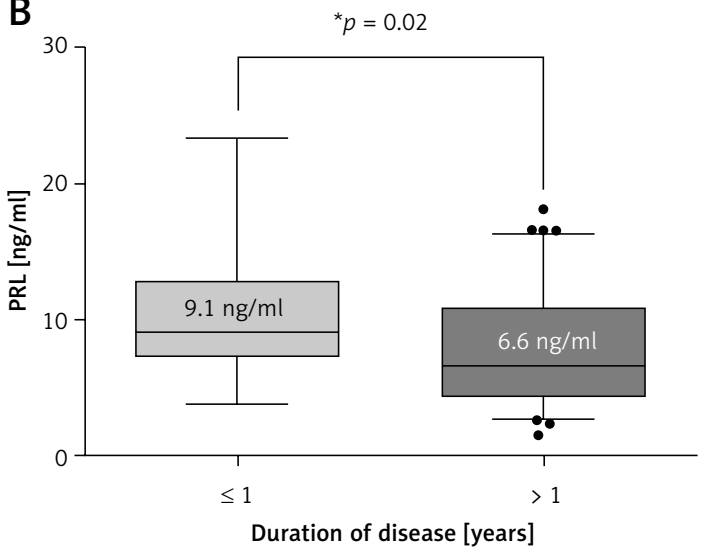

D

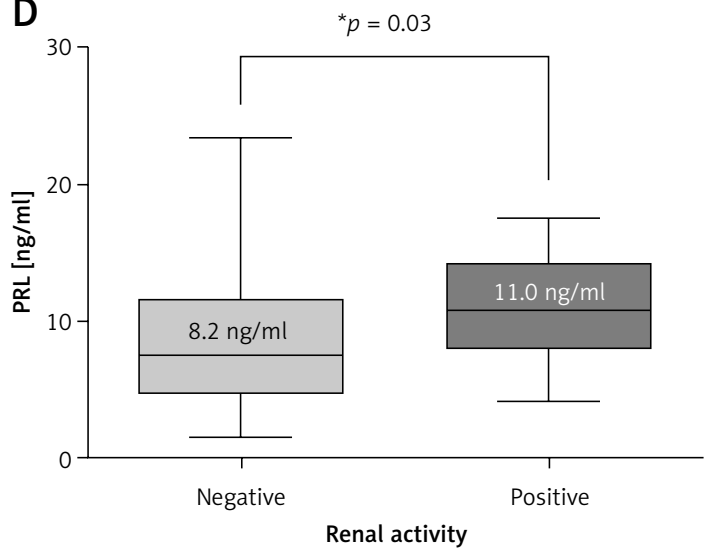

Figure 1. Serum levels by study groups and correlation of PRL levels with clinical characteristics in SLE. A - Prolactin serum levels in SLE patients and CS; $\mathbf{B}$ - prolactin serum levels in SLE according to duration of disease; C - prolactin serum levels in SLE according to anti-RNP seropositivity; D - prolactin serum levels in SLE according to renal activity. Numbers indicate median values. Boxes show $25-75 \%$ data ranges, whiskers show $5-95 \%$ ranges, and circles show outliers outside the $5-95 \%$ ranges. Statistical analysis was performed using the Mann-Whitney $U$ test 


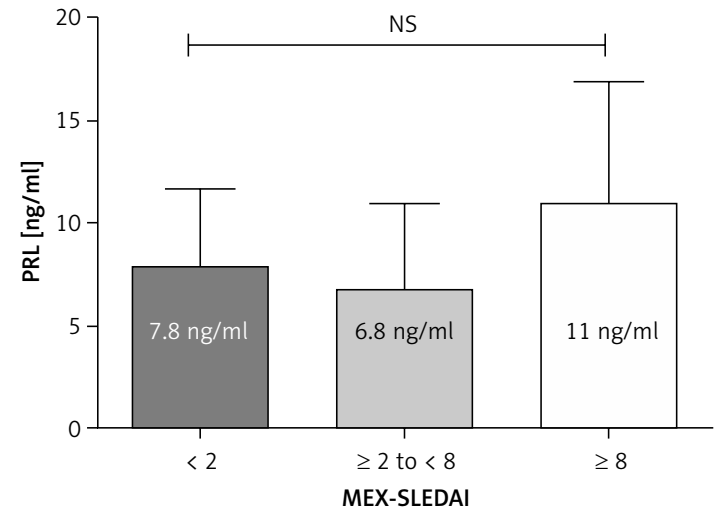

Figure 2. Prolactin (PRL) serum levels from SLE patients according to Mex-SLEDAI score. Data provided as median (p25-p75). The three groups of patients had similar disease duration to avoid our results being affected by this variable. Statistical analysis was performed using the Kruskal-Wallis test

NS - not significant, $p$-value $>0.05$

\section{Discussion}

In this study we investigated whether there is relationship between the extrapituitary $P R L$ promoter polymorphism $-1149 \mathrm{G} / \mathrm{T}$ and susceptibility to SLE in the Mexican population. This polymorphism has been studied in several autoimmune diseases such as multiple sclerosis [20], psoriatic arthritis [26], systemic sclerosis [27], rheumatoid arthritis [4] and SLE [18, 19]. Nevertheless, to date this is the first study to evaluate the association of the $P R L-1149 \mathrm{G} / \mathrm{T}$ polymorphism with SLE in patients from the western Mexico.

We found significant differences between genotypic frequencies of $P R L-1149 \mathrm{G} / \mathrm{T}$ SNP in the comparison by groups, with a higher frequency of the TT genotype in the patient group than the control group. To confirm this result, we performed a recessive genetic model, finding a similar significant difference, according to this inheritance model the risk for SLE is modified only when two copies of the polymorphic $T$ allele are present. These results are different from those reported in previous studies conducted in Czech [19] and Central Mexico populations with SLE [18], where they did not find an association between the PRL $-1149 \mathrm{G} / \mathrm{T}$ SNP and SLE. In this regard, our results suggest that this polymorphism is a risk marker for SLE in the population from western Mexico, due to higher frequency of TT genotype in these patients. These inconsistencies between the studies may be explained in part by differences in the studied populations and sample sizes used, because it has been reported that these are the main reasons leading to lack of statistical power to detect low magnitude associations [25]. Besides, this can be explained by our racial influence, it having been reported that there are differences in the genetic component even among

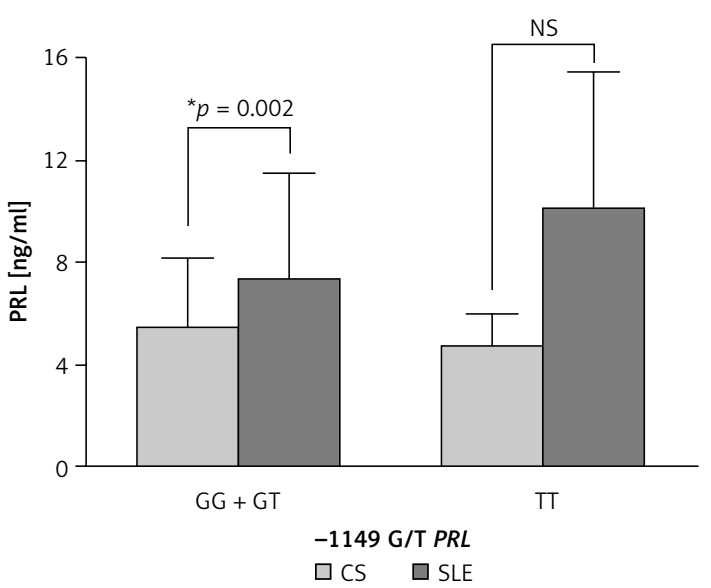

Figure 3. Prolactin serum levels by $-1149 \mathrm{G} / \mathrm{T}$ PRL genotypes according to a dominant genetic model. Data provided as median (p25-p75). Statistical analysis was performed using the Mann-Whitney $U$ test NS - not significant, $p$-value >0.05, CS - control subjects, SLE - systemic lupus erythematosus.

regions of our country, as in the case of western Mexico and Central Mexico [28].

On the other hand, when we correlated the presence of the $P R L-1149 \mathrm{G} / T$ genotype with the clinical characteristic of the SLE patients according to the recessive genetic model, we found that the TT genotype carriers have higher scores in the SLICC damage index with respect to the GG + GT genotype carriers $(p=0.02)$. Notably, we found significant differences according to seropositivity for anti-RNP in patients with TT genotype versus patients with GG + GT genotype $(p=0.04)$.

Previous studies have found an association between the $G$ allele and the presence of autoantibodies in patients with both SLE and RA $[8,18]$. One explanation for this could be that the T allele is associated with low promoter activity and decreased mRNA expression in comparison with the $\mathrm{G}$ allele, because it can produce a GATA-3 binding site in the prolactin promoter, which may be acting in an inhibitory mode. However, it has been suggested that additional factors may be involved in GATA-3 binding in the two alleles. Therefore it is possible that those factors are involved in binding to the -1149 element and modify the magnitude of activation [8]. Another aspect to consider is the differences in the microenvironment of each disease, because, similarly to prolactin, there may be other molecules, such as IL-10, which increase antibody synthesis in B cells in a dose-dependent manner, and production of this cytokine is higher in peripheral blood mononuclear cells (PBMCs) from SLE patients compared to RA patients [29]; hence IL-10 in interaction with other cytokines could be masking the effect attributed to $P R L$ $-1149 \mathrm{G} / \mathrm{T}$ polymorphism in SLE patients.

In the case of protein serum levels, we observed higher PRL serum levels in SLE patients 
vs. CS (SLE $7.5 \mathrm{ng} / \mathrm{ml}$ vs. CS $5.3 \mathrm{ng} / \mathrm{ml}, p<0.001)$. These results are similar to those of several studies which support the role of PRL as an important modulator in immunoresponse and its participation in autoimmune diseases such as SLE [12, 30, 31]. Also we evaluated the relationship of the PRL serum levels with the $-1149 \mathrm{G} / \mathrm{T}$ SNP according to a recessive genetic model in both study groups, and we found a significant difference in frequency of the GG + GT genotype $(p=0.002)$ and a non-significant difference in frequency of the TT genotype. These results indicate that independently of genotype, there is an increase in the PRL synthesis in SLE patients. This deregulation may be due to the pathophysiological process occurring in SLE patients, which may promote the secretion of this hormone and lead to alterations in the PRL values, unlike the CS, in whom PRL serum levels are not directly related to the pathological process.

In addition, we found a negative correlation between soluble PRL levels and age $(r=-0.33$, $p<0.001)$, indicating that PRL serum levels tend to decrease with age, which is similar to the observation reported by Vekemans and Robyn, 1975 [32]. Further, higher PRL serum levels were observed in patients with $\leq 1$-year duration of disease $(9.1 \mathrm{ng} /$ $\mathrm{ml}$ ) compared with patients with over 2-year duration of disease $(6.6 \mathrm{ng} / \mathrm{ml})$, with a statisticlly significant difference $(p=0.02)$. These results could suggest that PRL may be altered in early SLE and may participate significantly in the development of the disease manifestations, similar to observations previously reported in SLE murine models [33]. Likewise, we found that SLE patients with higher PRL serum levels showed higher Mex-SLEDAI index scores, but this difference was not significant. However, these findings are consistent with a previous study which found a positive correlation of PRL serum levels with disease activity [34].

Another important finding was the observation of higher PRL serum levels in seropositive patients for all analyzed autoantibodies in this study (dsDNA, anti-Ro, anti-La, anti-Sm and anti-RNP) compared to seronegative patients, but we only found a significant difference for the anti-RNP antibodies $(p=0.004)$, suggesting that PRL may be an important stimulating $B$ cell factor which promotes autoantibody production. This hypothesis is supported by Jacobi et al., who reported an association between soluble PRL levels and antibodies (anti-dsDNA and anti-cardiolipin) [12]. In addition, the ability of PRL to induce autoantibody production by PBMCs of SLE patients, possibly by T cell activation (via JAK2 and Stat5), mediated by interaction with the $P R L$ receptor ( $R-P R L)$, has been described. This leads to production and release of a variety of cytokines including IL-1, IL-4, IL-5, IL-6, IL-10, and IFN- $\alpha$, which stimulate the prolifer- ation and differentiation of B cells [35]. Thus these findings support the view that PRL promotes the breakdown of immunological tolerance, which is preponderant in SLE.

On the other hand, we also found that patients with renal activity had higher PRL serum levels than did those without these manifestations, suggesting that PRL could contribute to greater severity of disease. A similar relationship between PRL and renal activity was reported by another study [11]. Moreover, one report suggested that HPRL is related to lupus nephritis, because elevated PRL and IL-6 levels were found in serum and urine of SLE patients with kidney disease [36, 37]. These results support the hypothesis that PRL and IL- 6 can be accumulated in the kidney (in inflammatory processes) and activate the $T$ and $B$ lymphocytes in infiltrates in renal tissue, which leads to the perpetuation of inflammation; thus, the high concentrations of PRL and IL- 6 in the urine of these patients may be the result of local synthesis of both mediators [10].

In conclusion, this study showed that the $P R L$-1149 TT genotype is a susceptibility marker for SLE in a population from western Mexico. Moreover, SLE patients presented elevated PRL serum levels, and this condition was associated with renal activity and the presence of anti-RNP antibodies. Therefore due to the important roles of prolactin in several autoimmune diseases, further investigations in this context will be required to clarify the role of $P R L-1149 \mathrm{G} / \mathrm{T}$ SNP in the pathophysiology of SLE.

\section{Acknowledgments}

The study was supported by funding from the National Council of Science and Technology (CONACYT) grant no. 161749 (Fondo Sectorial Secretaría de Salud-IMSS-ISSSTE-CONACYT-México-Universidad de Guadalajara) assigned to JFMV.

\section{Conflict of interest}

The authors declare no conflict of interest.

\section{References}

1. Koutsokeras T, Healy T. Systemic lupus erythematosus and lupus nephritis. Nat Rev Drug Discov 2014; 13: 173-4.

2. Tsokos GC. Systemic lupus erythematosus. N Engl J Med 2011; 365: 2110-21.

3. Petri M. Epidemiology of systemic lupus erythematosus. Best Pract Res Clin Rheumatol 2002; 16: 847-58.

4. Reyes-Castillo Z, Pereira-Suárez AL, Palafox-Sanchez CA, et al. The extrapituitary prolactin promoter polymorphism is associated with rheumatoid arthritis and anti-CCP antibodies in Mexican population. Gene 2013; 525: 130-5.

5. Marano RJ, Ben-Jonathan N. Minireview: extrapituitary prolactin: an update on the distribution, regulation, and functions. Mol Endocrinol 2014; 28: 622-33. 
6. Beda-Maluga K, Pisarek H, Romanowska I, Komorowski J, Świętosławski J, Winczyk K. Ultrafiltration - an alternative method to polyethylene glycol precipitation for macroprolactin detection. Arch Med Sci 2015; 11: 1001-7.

7. Orbach H, Zandman-Goddard G, Boaz M, et al. Prolactin and autoimmunity: hyperprolactinemia correlates with serositis and anemia in SLE patients. Clin Rev Allergy Immunol 2012; 42: 189-98.

8. Stevens A, Ray D, Alansari A, et al. Characterization of a prolactin gene polymorphism and its associations with systemic lupus erythematosus. Arthritis Rheum 2001; 44: 2358-66.

9. Harvey S, Arámburo C, Sanders EJ. Extrapituitary production of anterior pituitary hormones: an overview. Endocrine 2012; 41: 19-30.

10. Jara LJ, Vera-Lastra O, Miranda JM, Alcala M, AlvarezNemegyei J. Prolactin in human systemic lupus erythematosus. Lupus 2001; 10: 748-56.

11. Pacilio M, Migliaresi S, Meli R, Ambrosone L, Bigliardo B, Di Carlo R. Elevated bioactive prolactin levels in systemic lupus erythematosus: association with disease activity. J Rheumatol 2001; 28: 2216-21.

12. Jacobi AM, Rohde W, Ventz M, Riemekasten G, Burmester GR, Hiepe F. Enhanced serum prolactin (PRL) in patients with systemic lupus erythematosus: PRL levels are related to the disease activity. Lupus 2001; 10: 554-61.

13. Karimifar M, Tahmasebi A, Bonakdar ZS, Purajam S. Correlation of serum prolactin levels and disease activity in systematic lupus erythematosus. Rheumatol Int 2013 33: 511-6.

14. Mok CC, Lan CS, Tam SC. Prolactin profile in a cohort of Chinese systemic lupus erythematosus patients. $\mathrm{Br} J$ Rheumatol 1997; 36: 986-9

15. Orbach H, Shoenfeld Y. Hyperprolactinemia and autoimmune diseases. Autoimmun Rev 2007; 6: 537-42.

16. Ignacak A, Kasztelnik M, Sliwa T, Korbut RA, Rajda K, Gu zik TJ. Prolactin - not only lactotrophin. A "new" view of the "old" hormone. J Physiol Pharmacol Off J Pol Physiol Soc 2012; 63: 435-43.

17. Gerlo S, Davis JRE, Mager DL, Kooijman R. Prolactin in man: a tale of two promoters. BioEssays News Rev Mol Cell Dev Biol 2006; 28: 1051-5.

18. Montoya-Díaz E, Cervera-Castillo H, Chávez-Sánchez L, et al. Prolactin promoter polymorphism $(-1149 \mathrm{G} / \mathrm{T})$ is associated with anti-DNA antibodies in Mexican patients with systemic lupus erythematosus. Immunol Invest 2011; 40: 614-26.

19. Fojtíková M, Cerná M, Cejková P, Ruzicková S, Dostál C. Extrapituitary prolactin promoter polymorphism in Czech patients with systemic lupus erythematosus and rheumatoid arthritis. Ann Rheum Dis 2007; 66: 706-7.

20. Mellai M, Giordano M, D'Alfonso S, et al. Prolactin and prolactin receptor gene polymorphisms in multiple sclerosis and systemic lupus erythematosus. Hum Immunol 2003; 64: 274-84.

21. Hochberg MC. Updating the American College of Rheumatology revised criteria for the classification of systemic lupus erythematosus. Arthritis Rheum 1997; 40: 1725.

22. Gladman D, Ginzler E, Goldsmith C, et al. The development and initial validation of the Systemic Lupus International Collaborating Clinics/American College of Rheumatology damage index for systemic lupus erythematosus. Arthritis Rheum 1996; 39: 363-9.
23. Miller SA, Dykes DD, Polesky HF. A simple salting out procedure for extracting DNA from human nucleated cells. Nucleic Acids Res 1988; 16: 1215.

24. Reyes-Castillo Z, Palafox-Sánchez CA, Parra-Rojas I, et al. Comparative analysis of autoantibodies targeting peptidylarginine deiminase type 4 , mutated citrullinated vimentin and cyclic citrullinated peptides in rheumatoid arthritis: associations with cytokine profiles, clinical and genetic features. Clin Exp Immunol 2015; 182: 119-31.

25. Lewis CM. Genetic association studies: design, analysis and interpretation. Brief Bioinform 2002; 3: 146-53.

26. Stolfa J, Fojtíková M, Cejková P, Cerná M, Sedová L, Dostál C. Polymorphism of the prolactin extrapituitary promoter in psoriatic arthritis. Rheumatol Int 2007; 27 : 1095-6.

27. Fojtíková M, Cejková P, Bečvář R, Vencovský J, Tomasová Studýnková J, Cerná M. Polymorphism of the extrapituitary prolactin promoter and systemic sclerosis. Rheumatol Int 2010; 30: 1691-3.

28. Rangel-Villalobos H, Muñoz-Valle JF, González-Martín A Gorostiza A, Magaña MT, Páez-Riberos LA. Genetic admixture, relatedness, and structure patterns among Mexican populations revealed by the Y-chromosome. Am J Phys Anthropol 2008; 135: 448-61.

29. Trifunović J, Miller L, Debeljak Ž, Horvat V. Pathologic patterns of interleukin 10 expression - a review. Biochem Med 2015; 25: 36-48.

30. Jimena P, Aguirre MA, López-Curbelo A, de Andrés $M$, Garcia-Courtay C, Cuadrado MJ. Prolactin levels in patients with systemic lupus erythematosus: a case controlled study. Lupus 1998; 7: 383-6.

31. Moszkorzová L, Lacinová Z, Marek J, Musilová L, Dohnalová A, Dostál C. Hyperprolactinaemia in patients with systemic lupus erythematosus. Clin Exp Rheumatol 2002; 20: 807-12.

32. Vekemans $M$, Robyn C. Influence of age on serum prolactin levels in women and men. Br Med J 1975; 4 738-9.

33. Legorreta-Haquet MV, Flores-Fernández R, Blanco-Favela F, et al. Prolactin levels correlate with abnormal B cell maturation in MRL and MRL/lpr mouse models of systemic lupus erythematosus-like disease. Clin Develop Immunol 2013; 2013: 287469.

34. Vera-Lastra O, Mendez C, Jara LJ, et al. Correlation of prolactin serum concentrations with clinical activity and remission in patients with systemic lupus erythematosus. Effect of conventional treatment. J Rheumatol 2003; 30 2140-6.

35. Hooghe R, Dogusan Z, Martens N, Velkeniers B, Hooghe-Peters EL. Effects of prolactin on signal transduction and gene expression: possible relevance for systemic lupus erythematosus. Lupus 2001; 10: 719-27.

36. Miranda JM, Prieto RE, Paniagua R, et al. Clinical significance of serum and urine prolactin levels in lupus glomerulonephritis. Lupus 1998; 7: 387-91.

37. Peterson E, Robertson AD, Emlen W. Serum and urinary interleukin-6 in systemic lupus erythematosus. Lupus 1996; 5: 571-5. 